DOI: $10.46523 /$ jarssc. 05.01 .05

Multidisciplinary, Open Access

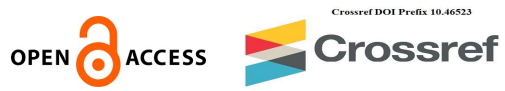

\title{
Mental Health of Secondary School Students: Issues and Challenges
}

\author{
Ms. Bharti Kumari \\ Research Scholar, School of Education, Central University of Haryana, Haryana, India \\ E-mail: bharti1101@gmail.com \\ Dr. Parmod Kumar \\ Associate Professor, School of Education, Central University of Haryana, India, \\ E-mail: pkyadav40@gmail.com
}

\begin{abstract}
The secondary school stage is the most important phase of life where students are facing physical, social, mental, family, educational, and personal problems. At this stage, mental health plays a very important role and helps to deal with these types of problems in a very effective way. Therefore, the paper assumes significance, being a genuine effort to study the issues and challenges in the mental health of secondary school students. The present paper is a review paper and based on some research studies related to mental health directly or indirectly. The results of the study revealed that the status of mental health in India is not in good condition due to various issues and challenges in terms of misconceptions about mental health, lack of awareness and resources, social, personal, financial, eco-system or environment and technology-related problems. It was also found the treatment gap \& non-availability of treatment-related resources and facilities. Prevention and cure are the essential requirements of mental health. Proper orientation and awareness about mental health issues and challenges at the secondary school level will be very helpful for students to cope up with the tense situations and also help in being well-adjusted in family and society. Thus, the findings of the present study are very useful for teachers, parents, administrators, and guidance workers to make necessary arrangement to provide a conducive environment at home and school so that the mental health of secondary school students can be improved.
\end{abstract}

Keywords: Mental Health, Secondary School Students, Issues, and Challenges. 
DOI: $10.46523 /$ jarssc.05.01.05

Multidisciplinary, Open Access

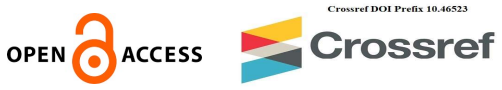

\section{INTRODUCTION}

Mental Health comprises positive behaviour, mind activities, feelings, emotions, etc. which is difficult for people to always keep on the right track. Secondary school students can easily way off because at this age, their mind gets disturbed by the stress and storm of external and internal dilemmas.Students are facing many problems due to mental health issues in India. The last few years have been very challenging for developing countries like India. Recent pandemics, natural and unnatural disasters, and differences in personal and professional relationships have deeply affected mankind. These events have had a very profound effect like depression, stress, anxiety, fatigue, etc., among peoples. So, in the contemporary era, students are facing various problems like sleeplessness, social disorder, emotional instability, suicidal attitude, fear of deteriorating social status, etc. Bhatia(2020) highlighted that"The proportion of the contribution of mental disorders in India has almost doubled since 1990 and it leads one out of every seven Indians in 2017 with a variety of mental disorders".Therefore, the present paper is a genuine effort to study the issues and challenges in the mental health of secondary school students. It is a review paper and based on some research studies related to mental health directly or indirectly.

\section{STATUS OF MENTAL HEALTH IN INDIA}

In India, around $41 \%$ population is less than 18 years of age (Kumar, Nayar, \& Bhat, 2020). In this phase, adolescents are involved in dealing with several issues of their lives without any experiences, and also possess very less knowledge and information. They think that their knowledge and experiencesare sufficient to understand the whole world, but they do not understand the outside world and get entangled in the issues of life seeing the challenges of life.Indian population holds the world's second position of more than 1.236 billion (UNICEF, 
DOI: $10.46523 /$ jarssc.05.01.05

Multidisciplinary, Open Access

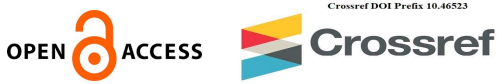

India, 2013), out of the total population, every third person belongs to 10 and 24 years of age, and every fifth person found to be a juvenile between 10 and 19 years of age (Census of India, 2011). It shows that India is holding the largest young population with over 434 million in the world (UNICEF, India, 2013). By 2030, it is expected to grow to around 250 million working people, as one of the huge demographic dividends (Reuters, 2016). It is like an asset to contribute to the growth and development of any country. All progress can be expected if the policy area gives priority to the health of children and adolescents (Hossain \& Purohit, 2019).It has also increased the number of problems related to mental health.

In India, the focus on infant immunization, nutrition, and mortality has led to an overall increase in physical health, but are not paying much attention to the mental health of school-going adolescents and children (MHFW \& GOI, 2005). More than 50 million children including school students are found suffering from mental illness in India, and if the adolescent population is also considered as a whole, this number will increase further (Shastri, 2009).

Mental health issues ranked from one of 6 primary strategies of the National Adolescent Health Strategy, namely- Rashtriya KishorSwasthyaKaryakram (MHFW\& GOI, 2015). The target population for the programme was between 10-19 years, but the peer educators selected them from 15 to 19 years only. It reduces the accessibility of children between $0-10$ years to counselling services. The objective of the programme was to raise awareness and also provided psychological or clinical support to those who require it. Although the programme was intended to solve the overall problems of adolescent health, it appeared insufficient even to address the problems related to the mental health of the children and adolescents in India (Hossain \& Purohit, 2019). 
DOI: $10.46523 /$ jarssc.05.01.05

Multidisciplinary, Open Access

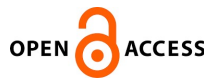

Crossref

\section{MENTAL HEALTH OF SECONDARY SCHOOL STUDENTS: ISSUES AND}

\section{CHALLENGES}

Secondary school students are facing various problems related to mental health. Sharma (2017) indicated that stress, depression, anxiety were the major challenges for mental health in the modern era. A detailed description of some issues and challenges of mental health faced by the secondary school students are given below:

(i)Misconceptions about Mental Health: Mental health is often taken as a mental illness, which is wrong. Unlike mental illness, mental health is a desirable quality in itself. It is also a misconception that mental health is the absence of any disease. Harmonious working of all the potentials in all the aspects of individuals is the balanced personality but cannot be taken as mentally healthy. Many a times, children who worked efficiently, active, and achieved success in their field were also not mentally sound (Sharma, 2017). Mental health can be related to many positive and negative outcomes such as educational attainment, violence, reproductive and sexual health, and substance abuse (Patel, Fisher, Hetrick, \&McGorry, 2007), but it always refers to positivity or to gain positivity. It is also a big challenge to remove this misconception from the mind of parents, community/society. This misconception adversely affects the mind of children, creates discrimination in them, and forces them to think differently from society.

(ii)Lack of Awareness and Resources: It is a challenging issue these days to access the proper resources and information at the right time. There is a bundle of information around us due to technological enhancement which has created major confusion to identify the right information, it creates stress and anxiety. Lack of adequate resources such as specialists, policies, procedures, and adequate facilities and services was a hindrance in the mental care of adolescents (WHO, 
DOI: $10.46523 /$ jarssc.05.01.05

Multidisciplinary, Open Access

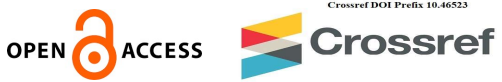

2003; United for Sight, 2015; Hossain, \& Purohit, 2019).Mental health is absent from the mainstream health policy, to bring it back into the mainstream was a great challenge (Hossain, \& Purohit, 2019). To improve the mental health situation in India, several provisions have been made under the Mental Health Care Act, 2017, which repeals the 1987 Act, which was criticized for several reasons (Mishra and Galhotra, 2018). All people with mental health problems in India were not having access to quality services. The treatment interval for normal mental problems was $95 \%$ more than the interval for severe problems which was $76 \%$ (MHFW, \& GOI, 2016). So, lack of information and resources is a big issue in the recent environment. At the same time, it is a challenge to have the right information, the availability of resources, and manage it effectively.

(iii) Social Dilemma: Social relations, families, communities and society play an important role in adolescents' mental health. It also helps mentally affected children to access the necessary treatment, but mental health is a serious issue that must be acknowledged at every level of family and society.Fear of society leads to under-reporting of such incidents and delay in reporting more serious mental problems, seriously deteriorating the mental health of the victim (Shastri, 2009; Hossain, \& Purohit, 2019). In India, most of the services related to mental health are centralized, also the coordination between central health services and community demands was poor, and health systems had improved over the past 70 years, but this situation has not been addressed much (Malhotra, 2004). The delivery of such services to the needy in India was not adequately arranged, managed, and a lack of stakeholder participation was noted (Simpson \& House, 2001; Shastri, 2009; Hossain, \& Purohit, 2019). To remove the social sigma and decentralization of facilities \& services are also a big issue and challenge. 
DOI: $10.46523 /$ jarssc.05.01.05

Multidisciplinary, Open Access

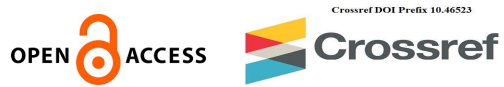

(iv)Financial Problem: Finance has always been a major requirement in an individual's life as livelihood depends on financial resources. Today's children are very sensitive about financial matters. Its insecurity affects children emotionally.Emotionally disturbed children may experience many psychological issues like insomnia, anxiety, low mood, and loss of appetite (Kumar, Nayar, \& Bhat, 2020). According to WHO, mental health disorders cause an economic loss of USD 1.03 trillion to India between 2012-2030 (Bhatia, 2020; Bernadine, 2021). Mental health budgets are low in low-income countries, with $0.06 \%$ of the whole national health budget allotted for mental health (WHO, 2011; Hossain, \& Purohit, 2019).

(v) Personal Mental Conflicts: Lack of goal in life, entertainment, negative self-concept, etc. in individual lives leads to their mental illness. Due to this, children start withdrawing from the outside world and start isolating themselves. They become unable to recognize their worth in the world, or find themselves worthless and attracted to negative thoughts of suicide, criminal activities, etc. Erik Erikson who is a well-known developmental psychologist has first used the term "identity crisis" in which he has also said that the adolescence stage is very sensitive toward their identity. In this phase, their identity included their attitudes about love, sex, marriage, gender roles, and several other important issues related to their lives (Hashmi, 2013). Developing self-concept, respect, self-confidence, etc. in school students and adolescents is a big challenge. Although, it has been mentioned in the NEP-2020 to implement it and it is collective responsibilities of allthe stakeholders to come forward in this matter.

(vi) Eco-System or Environmental Effects: Natural and unnatural disasters and frequent changes in the environment also affect the mental status of a child. Recent pandemic has drastically changed the life of an individual, it has also affected everyone's mental health and 
DOI: $10.46523 /$ jarssc. 05.01 .05

Multidisciplinary, Open Access

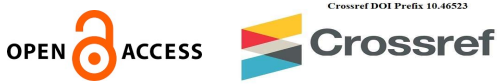

changed several concepts and daily life's routine. Several agencies that work on children's issues expect that the increase in stress and anxiety of families due to COVID-19 will lead to mental problems of children (APA, 2020). To address these problems, agencies and professionals in various countries have come forward to make available counselling and support related to psychosocial services. These types of services are often not well-organized for children (Dong \& Bouey, 2020). Kids who lost their parents in COVID-19 are found highly vulnerable. Children who were in bereavement can be victims of many psychological issues like insomnia, anxiety, low mood, and appetite problems (Kumar, Nayar, \& Bhat, 2020). Adversities can be divided into three categories that have affected children, viz. (i) people due to COVID-positive symptoms are isolated; (ii) children whose parents are COVID-positive and due to infection those who have lost parents; and (iii) due to general lockdown children in isolation. Different categories of children have faced different types of mental health problems (Kumar, Nayar, \& Bhat, 2020). Opposite to the general belief that the COVID was not fatal to children, children under the age of 12 were also infected in India (TNIE, 2020). In 2021, recent studies, many news articles, and magazines highlighted that the COVID-19 pandemic is still raising the rate of anxiety, stress, and depression in more than 204 countries. The issue is how to sensitize people to such incidents so that they can prepare in advance and support each other in such situations. Preparation for these events is a major challenge as it is not always a controlling factor.

(vii) Technological and Educational Complications: Problems at work due to overuse of mobile phones have been reported in the Indian media, mostly adolescents or within the 10-15 age group, with males being affected more than females (Coggon, 2005; Anboucarassy \& Begum, 2014; Suvarna, 2020). An increase in digital connections may promote 'emotional 
DOI: $10.46523 /$ jarssc. 05.01 .05

Multidisciplinary, Open Access

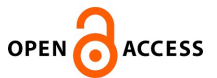

transition' in which feelings like fear and distress can be spread from one to another (Gao et al, 2020). Due to over texting and frequent use of electronic media and equipment, children are now detaching from their families due to the loss of emotions, feeling, warmth \& closeness (Maier, 2000), and become a reason for increased conflict and disagreement between children and their parents. It has been found that students usually send 100 SMS per day or more than 3000 SMS per month also make or receive 150 calls per month and five calls in a day (Anboucarassy \& Begum, 2014). Students are unable to understand the ill effects of mobile radiation (Hermann, \& Hussmann, 2003). A variety of problems have been found in students who use mobile phones excessively (Hutter, et al., 2006), such as sleeplessness, depression, drug addiction, feeling stressed, fear of missing out, impulsivity, and isolation. Due to fast-growing liberalization and global market, today education has converted into a business sector in the hands of private organizations, and students are treated as machines and expected to achieve higher marks to increase the market value. Parents are facing challenges under constant pressure for their children to provide effective job-oriented education. Public and private schools are discriminating between students in taking education. To beat the competition and secure higher seats in education, students were burdened with additional classes and coaching. Parents pressurize children beyond their limits due to the comparison and competition. Hence, as a result, students' focus has been diverted toward getting a job rather than understanding subjects. And these constant pressures were affecting the mental health of students (Subramani \&Kadhiravan, 2017). The point is that we cannot separate technology and education from our lives and it is a challenge to teach school-going children to use technology and manage stakeholders' expectations properly and effectively so that it does not affect mental health. 
DOI: $10.46523 /$ jarssc.05.01.05

Multidisciplinary, Open Access

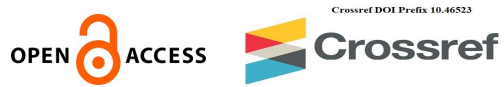

(viii) Availability of Facilities and Services, Treatment Gap: Less than $01 \%$ of children and adolescents received mental disorder treatment (Shastri, 2009). Whereas severe disorders required multi-specialty care among which learning, speech, visual, hearing, and personality disorders were prominent, for which good facilities were not available even in urban areas. Needy populations who live on the street, or orphanages, rescue homes, juvenile homes, and many other similar places can be the cause of children and adolescents' mental illness are given little attention (Vostanis, 2010). The gap between the affected person and the service providers offering facilities was a barrier due to the lack of health services in rural and urban areas (WHO, 2003; Harrison, 2018; Reddy, et al., 2014). In 2015-16, according to the National Mental Health Survey, nearly $80 \%$ of people with mental disorders did not receive treatment for over a year, ranging from $28 \%$ to $83 \%$ across various mental disorders (NIMHANS, 2016). Also, the absence of primary services in mental health and healthcare was found (Ginneken, Jain, Patel, \& Berridge, 2014). 'WHO' revealed that,there were only 0.07 social workers, 0.07 psychologists, 0.12 nurses and 0.3 psychiatrists, while the desired number was above 3 psychiatrists and psychologists per 100,000 populations in India (Bhatia, 2020). The point is to identify the right facilities and services for children in need. In such a situation, it is a big challenge to recognize and fill the gap associated with the right treatment.

\section{REMEDIAL MEASURES TO IMPROVE MENTAL HEALTH OF SECONDARY SCHOOL STUDENTS}

Keeping in view, the issues and challenges of mental health, the following remedial measures are suggested by the researchers for further improvement of mental health of secondary school students: 
DOI: $10.46523 /$ jarssc. 05.01 .05

Multidisciplinary, Open Access

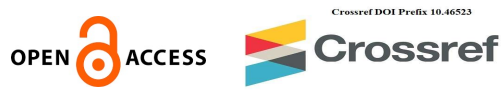

(i) Proper Diagnosis of Issues Related to Mental Health: The first and foremost task is to understand the problem at both the surface and the depth level for taking remedial measures. An effective strategy for diagnosing the problem should be designed for a better understanding of the problem. Diagnosis should be performed in the following areas:

- Physical diagnosis: First of all, it is important to identify children who are physically healthy, and do not have any physical disabilities that can affect their brain.If they have any general physical problems, they should be referred to a doctor or concerned specialist instead of a psychiatrist. Long-term common physical problems can affect mental health.

- Psychological diagnosis: If children are physically normal yet behave differently than usual, they may have some kind of mental problem. It is also not true that children are mentally healthy if they are behaving or responding properly. It is always necessary to closely monitor the thinking process, physical activities, and behavior of children and adolescents. While observing this, care should be taken that the child does not know and does not get angry. While watching this, care should be taken that the children do not know that someone is observing them and do not feel offended.

- Genetics diagnosis: It is also important to go through the medical and other histories of the children's family. Sometimes the reason for the bad mental and physical behavior of children is related to their parents and family. If the child is not doing well in the class despite being told repeatedly, then one of the reasons may be related to the parents or family, this should be taken care of before providing the treatment.

- Environmental diagnosis: It is also very important to check the environment around the child. The study of child development proves that the environment has a great influence 
DOI: $10.46523 /$ jarssc. 05.01 .05

Multidisciplinary, Open Access

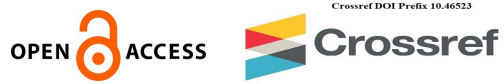

on the child's brain. In such a situation, if the child does not perform well, instead of providing mental treatment, stakeholders should try to improve the environment around him.

(ii) Proper Orientation and Awareness about Mental Health: Healthy body and mind accurately represent good health, both directly or indirectly affecting health. Health is the combination of both body and mind to work efficiently and harmoniously. The fundamental factors that contribute to maintaining physical health and social effectiveness are mental health.Well-adjusted children, who possess socially desirable good physical health and moral values, were seen as mentally healthy. A person of good mental health was happy, healthy, and hopeful (Sharma, 2017). Everywhere one has to make adjustments, sometimes the adjustments with the person him/her selves, with society, environment, etc. They have to learn how to make adjustments. Children are not obliging another person by adjusting with others and environments. They have to take care of how to create harmonious relations with others, with the environment, and with themselves. For this purpose, every year $10^{\text {th }}$ October is observed as Mental Health Day and celebrated everywhere in the world. So proper orientation of all the stakeholders are also very important so that they can provide a conducive environment everywhere inside or outside the home and institutions to children.

(iii) Guidance for Maintaining Mental Hygiene: Mental Hygiene is a way or strategy how one can be and achieve mental health. Klien said that "Mental Hygiene is the study of ways and means of keeping the mind healthy and developing". So one should learn how to identify the sources and stay away from stress, anxieties, and be safe from being mentally ill. The strategies should find out how and to what extent youngsters are responsible for spoiling his or her mental 
DOI: $10.46523 /$ jarssc.05.01.05

Multidisciplinary, Open Access

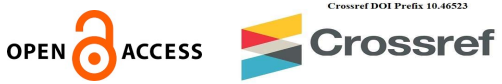

health and to what extent the internal or external environment is responsible for their mental illness (Sharma, 2017). The first child guidance clinics were established in the year 1937, the Indian Council for Mental Hygiene came into existence in the 1940s, and these establishments are described as the first initiatives to address the Indian problems related to the mental health of teens (Parkar, Dawani\&Apte, 2001).

(iv) Effective implementation of the Policy:Despite such seriousness and magnitude of teens' mental health problems, there was a lack of proper administration and comprehensive policies for children and adolescents related to mental health for the population of more than 435 million kids and teens (Malhotra \& Patra, 2014). National authorities of medical sciences, from 1991 to 1995, actively participated in the development of mental health of children and adolescents in the academic field and organized their fellowships in psychiatry (Malhotra, 2004), but some gap was found. In addition, India has adopted many more national policies in various areas of development of children, including the National Policy on Children (1974) and Education (1986), in 1987 Act for Mental Health, in 1993 National Nutrition Policy, The National Trust for Welfare of Persons with Cerebral Palsy, Autism, Multiple Disabilities, and Mental Retardation Act 1999, in 2004 the Charter for Children, and in 2005 the National Plan of Action for Children, but none of these took mental health of children and adolescents seriously. In 2002 and 2016, The National Health Policy and the National Mental Health Policy (2014) took little interest in the mental illness of the young population (MHFW, \& GOI, 2014; Hossain, \& Purohit, 2019). The programs, like the National Mental Health Program and the District Mental Health Program, contribute to the basic or primary psychiatric care for people in basic need, but still do not place special emphasis on the mental health of children and adolescents (Murthy, 2007). Policies 
DOI: $10.46523 /$ jarssc.05.01.05

Multidisciplinary, Open Access

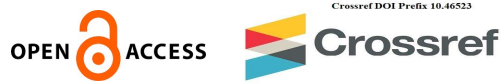

should be made for the use of technologies like mobile phones to safeguard the mental health of adolescents in India (Anboucarassy\& Begum, 2014).

In 1982, The National Mental Health Programme came into existence, to provide different mental health facilities and to make it a part of the basic healthcare system on WHO's recommendation. It has been successful in improving the situation at the community level, but inadequate infrastructure and lack of resources have limited its effectiveness (Gupta and Sagar, 2018). Policies must continue to evolve to deliver desired outcomes after implementation, for this purpose it requires strong determination of key stakeholders and an empirical or scientific way to convert that motivation into policy action (Hossain \& Purohit, 2019).

Good policies on mental health for children and adolescents in India may incorporate several principles related to WHO guidelines, such as (a) developing exclusive mental health care facilities, (b) By integrating mental health through basic health care, (c) ensuring the availability, access and equitable distribution of essential resources and facilities in rural and urban areas, (d) the environment around the school and home should be conducive for optimal development, and (e) Children and adolescents should also be involved in taking responsibilities and decisions in the planning of programs related to the mental health (WHO, 2005). Well sketched challenges and constraints can be mitigated by keeping a proactive approach, using the comprehensive method, integration, and multi-sectored approach(Hossain, \& Purohit, 2019). So, the following important points should be kept in mind while framing policy for mental health: 
DOI: $10.46523 /$ jarssc. 05.01 .05

Multidisciplinary, Open Access

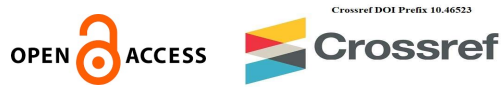

- There should be provision for policymaking at the central level and the delivery of facilities and services should be decentralized and reporting should be done at the central level.

- Research committees should be set up responsible for reporting all kinds of mental health problems from minor to major, of all ages, which should be directed at the central level.

- Policies should be goal-oriented and outcome-based, result reports should be time-bound. Ground-level monitoring should be done, reporting should be done in a very strict manner

- Since the population is growing at a very fast rate, there is a lot of variability in its data, so a provision should be made to conduct the census study in 5 years instead of 10 years. Online mode will be very helpful in this regard.

- Appointment of experts, training, and programs should be organized for awareness, guidance, and counseling for all stakeholders.

In October 2014, the Ministry of Health \& Family Welfare came up with a wide range of options for the National Mental Health Policy, but its implementation remains a major challenge.

\section{(v) Collaboration, Coordination, and Harmonious Relationship among agencies/}

stakeholders:In the past centuries, various types of events such as fairs, puppet shows, bioscopes, etc. were organized by the people, where children would go in groups and enjoy the environment together. But nowadays, children are overburdened with academic works, competitions, discrimination, etc. which has changed the motive of the environment of gathering and grouping. Now the sharing and caring concepts are also fainting, resulting in children feeling 
DOI: $10.46523 /$ jarssc.05.01.05

Multidisciplinary, Open Access

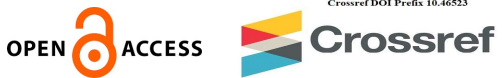

lonely and helpless which have become the major sources of mental illness. Previously social relations were emotionally connected, but now it is technologically connected which is promoting techno-stress among youth. Virtual reality has taken over the physical presence of relationships.

Stakeholders should take the initiative and conduct some activities and programs to provide a platform for physical collaboration for children. NIMHANS has helped in organizing some teacher's orientation programs, health programs, school-based campaigns, and student enrichment programs. It aimed to increase awareness regarding understanding themselves, psychosocial disorders, and improve interpersonal relationships with friends, neighbors, peers, and teachers (Hossain, \& Purohit, 2019). In a culturally diverse country like India where social relations are given a significant place, such values can help provide valuable direction for developing policies in this area (Snoeren et al., 2013).

Different programmes related to mental, physical, and social effects can improve mental health and can be helpful in the prevention of problems also will be helpful in social-emotional learning, life skills, resilience, character education, and mental health promotion (Payton et al., 2008; Weare, 2010; Durlak, Weissberg, Dymnicki, Taylor, \&Schellinger, 2011; Weare\&Nind, 2011; Petersen et al., 2016). It is the responsibility of family, teachers, communities and all the stakeholders' act according to the response they seek from a child. If a child will follow the positive and disciplined action their reaction will be to pursue them and gain a healthy mind.

(vi) Meditation and Yoga Programmes: From Vedic to modern period, meditation and yoga have always been in the trend as stress remover. Educational institutions should take active 
DOI: $10.46523 /$ jarssc.05.01.05

Multidisciplinary, Open Access

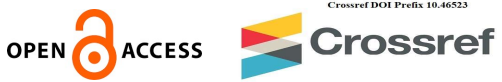

participation and should conduct periodical training programs for children and also to make parents aware of academic stress and ways to handle it efficiently. Teachers can use different strategies and interventions to reduce students' stress. Teachers should break down hard and lengthy tasks into small chunks that will be easy to do without stress. Yoga and meditation are the major sources to calm the mind and help develop health that makes people feel happy and also brings freshness in their lives (Sharma, 2012). It helps young people to cope with stress and to increase their ability to control and improve their thoughts and emotions. Yoga and meditation provide positivity, also decrease negative effects, and increase self-acceptance and awareness, lower the symptoms of anxiety, stress, depression, also increase attention, memory, concentration, academic achievement, improve the quality of life, and adolescents overall wellbeing (Mala, 2018).

\section{Conclusion}

Thus, based onthe above discussion, it may be concluded that secondary school students are facing various mental health related issues and challenges like lack of awareness, resources, facilities, services, social dilemmas, financial problems, personal \& mental conflicts, environmental \& technological complications, etc. which hamper their academic, social and personal life. Therefore, the present paper suggested some remedial measures for future improvement like the proper diagnosis of the mental health problems; proper orientation and awareness about mental health issues; adequate guidance services for mental hygiene, adequate policies \& implementation; meditation and yoga programs, harmonious relations, collaboration, and coordination among all the stakeholders. The present paper has its educational implications for policymakers, school administration/functionaries, teachers, parents, and agencies related to 
DOI: $10.46523 /$ jarssc.05.01.05

Multidisciplinary, Open Access

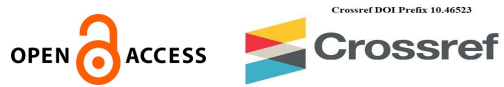

secondary education to provide conducive environment at home and school so that the mental health of secondary school students can be improved.

\section{ACKNOWLEDGEMENT}

The authors acknowledge all studies/reports that were directly or indirectly consulted during the course of the paper.

\section{REFERENCES}

- Bhatia, A. (2020 October, 9). World mental health day 2020: in numbers, the burden of mental disorders in India. NDTV. https://swachhindia.ndtv.com/worldmental-health-day-2020-in-numbers-the-burden-of-mental-disorders-in-india51627

- Hossain, M., \& Purohit, N. (2019). Improving child and adolescent mental health in India: Status, services, policies, and way forward. Indian Journal of Psychiatry, $61(4), 415-419$.

- Kumar, A., Nayar, K. R., \& Bhat, L. D. (2020). Debate: COVID-19 and children in India. Child and Adolescent Mental Health, 25 (3), 165-166.

- Malhotra, S. (2004). Child and adolescent psychiatry in India: Slow beginnings and rapid growth. Mental Health Indian Perspective. 244-9. https://mhpolicy.files.wordpress.com/2011/05/mental-health-e-book published10oct20041.pdf 
DOI: $10.46523 /$ jarssc. 05.01 .05

Multidisciplinary, Open Access

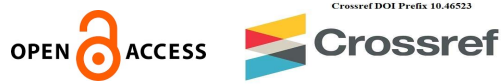

- Malhotra, S., \& Patra, B. N. (2014). Prevalence of child and adolescent psychiatric disorders in India: a systematic review and meta-analysis. Child and Adolescent Psychiatry and Mental Health, 8 (22), 1-9.

- MHFW, \& GOI. (2016). National mental health survey of India. http://www.indianmhs. nimhans.ac.in/Docs/Summary.pdf.

- MHFW, \& GOI. (2014). New pathways new hope: national mental health policy of India. https://www.nhp.gov.in/sites/default/files/pdf/national mental health policy of India 2014.pdf.

- MHFW, \& GOI. (2005). Burden of disease in India. http://www.who.int/macrohealth/action/NCMH_Burdenofdisease

- MHFW, \& GOI. (2015). Rashtriya Kishor SwasthyaKaryakram RKSK Guidelines. http://www.nhm.gov.in/nhm/nrhm/guidelines/nrhm-guidelines/arsh.

- Sharma, P. [ece]. (2017, February 1). Mental health [Video]. YouTube. https://www.youtube.com/watch?v=TkPJtxzZ7kI\&t=177s

- Shastri, P.C. (2009). Promotion and prevention in child mental health. Indian Journal of Psychiatry. 51(2), 88-95

- United for Sight. (2015). Barriers to Mental Health Care. United for Sight. http://www.uniteforsight.org/mental-health/module6.

- WHO. (2005). Child and adolescent mental health policies and plans. Mental Health Policy Service Guide 1-64. http://www.who.int/mental_health/policy/Childado_mh_module.pdf. 